\title{
A ARTE DE GERIR EUROPEIA, A COMPETIÇÃO E OS SEU LIMITES.
}

1. Helen BLOOM; Roland CALORI; Philippe de WOOT, L'Art du management européen, Paris, Les Éditions d'Organization, 1994, 150 p.

2. Grupo de Lisboa, Limites à competição (col. "Economia \& Gestão"), Lisboa, Publicações Europa-América, 1994, 210 p.

O folhear rápido e pouco atento dos dois livros em epígrafe podia levar-nos a concluir que estávamos em presença de obras com pouco em comum, ou se não mesmo divergentes. Todavia, concluída a sua leitura, apercebemo-nos precisamente do contrário. As obras em causa, não só radicam num universo de análise com muito em comum, como de alguma forma se completam. Vejamos, então, o que nos levou a esta conclusão: aparentemente, o tema central do primeiro livro prende-se com a magna questão da existência de um modelo de gestão especificamente europeu que, de algum modo, se distingue das formas de gerir americanas e japonesas. Contudo, apesar de ser esta a problemática nuclear do livro, o que, a cada passo, ressalta, sobretudo nos depoimentos de dirigentes e empresários, é a necessidade que todos sentem- numa fase em que se afirmam novos concorrentes, especialmente do Sudeste Asiático, e em que urge encontrar uma estratégia comum, no quadro criado pela União Europeia - de encontrar os meios que conduzam economicamente a Europa a uma posição competitivamente vantajosa. Ou seja: os autores procuram —mais do que isso estão esperançados nisso e desejam-no - encontrar no modo de gerir europeu características comuns que acabem por criar vantagens competitivas às empresas europeias.

Ora, o segundo livro mais não faz do que - tendo em conta precisamente esta mesma realidade de intensa luta pela conquista dos mercados mundiais - questionar esta escalada da competição económica. Alertando para o facto os agentes responsáveis e os cidadãos em geral, sobretudo para os perigos de uma competição sem limites. Competição que, no entender dos autores, a continuar sem inversão de sentido - precisamente entre a tríade: Japão, Europa e Estados Unidos da América -, provará, a muito curto prazo, que não será a melhor forma de resolver os grandes problemas do desenvolvimento à escala mundial. 
Os dois livros reflectem, assim, apesar das naturais diferenças de perspectiva e de posicionamento, uma mesma realidade: a consciência de se estar perante uma progressiva globalização dos processos económicos e, consequentemente, diante de uma "nova era de competição» que tornou ultrapassadas muitas das respostas baseadas no poder de influência e de decisão do Estado-Nação. Realidade emergente, a todos os níveis complexa que, por certo, obrigará os principais agentes a procurar novos modelos e conceitos, quer sobre a forma de lidar com ela, quer sobre os meios a utilizar para a sua compreensão.

É evidente, portanto, que os dois livros não fazem a mesma leitura deste novo quadro global que, todos sabemos, se encontra em plena fase de estruturação: os autores de L'art du management européen - mais perto das realidades empresariais e de um mundo em mudança, que tão pouco pára para que se reflicta sobre ele -, embrenhados que estão na luta pela conquista do mercado mundial, estão muito próximos de pensar que aquilo que é bom para as empresas acaba por ser positivo para as regiões, para os Estados e para as populações. Mais pragmáticos, sabem que, se a palavra de ordem é competir, só a fuga para a frente, antecipando-se aos concorrentes, sendo melhor do que eles, é que pode salvar economias, empregos, regiões, etc.. Saber, portanto, se o modelo de gestão europeu tem potencialidades de competir no mundo de hoje, ou quais as formas de melhor aproveitar as potencialidades culturais da Europa, na sua diversidade, para tornar as empresas ainda mais competitivas, dentro da tríade, $e$, no momento, a grande preocupação dos autores, empresários e governantes que o livro invoca.

Por sua vez, os autores de Limites à competição, conscientes de que alguém tem que reflectir sobre a Humanidade como um todo, bem como da necessidade de se questionar o caminho a que isto nos leva, acabam por justificar aquilo que no início dissemos, quando afirmámos que estes dois livros se completavam. Ou seja: o mundo está aí, a globalização económica e a competição são uma realidade, há que procurar as melhores formas de gestão que tornem as empresas mais competitivas. Mas se o caminho é este, ainda mais importante se torna que outros, porventura menos embrenhados na gestão quotidiana dos problemas, tenham a coragem de questionar o sentido e os efeitos desta competição. Sobretudo, interrogando os principais responsáveis para que respondam ao seguinte: a competição crescente, em que o mundo se encontra envolvido, será o melhor instrumento para enfrentar os cada vez mais graves problemas ambientais, demográficos, económicos, sociais, etc.? O grupo de Lisboa, e o livro Limites á competição, não se escusaram a demonstrar o contrário, bem como a apontar algumas soluções para inverter a situação. E procuraram fazê-lo sem negarem o quanto poderá ter de positivo uma sã competição que vise uma eficiente exploração dos recursos naturais e uma melhor e maior satisfação das necessidades individuais e colectivas.

As duas obras, como acabamos de ver, emergem de uma mesma realidade. Os 212 objectivos, a leitura e as respostas dessa mesma realidade, naturalmente não coin- 
cidem. Pensamos, ainda assim, que a sua leitura conjunta pode ajudar a equacionar a complexa realidade das coisas.

Vejamos, então, agora mais em pormenor, do que cada livro trata:

1. A obra L'art du management européen, com prefácio de Bertrand Collomb, retrata as conclusões de uma investigação, da qual foram responsáveis, em estreita colaboração, uma instituição de ensino superior (l'École Supérieure de Commerce de Lyon) e uma organização de empresários («La Table Rond Des Industrieles Européens» - associação de presidentes e directores gerais de cerca de quarenta empresas europeias (deste grupo faz também parte Américo Amorim, como presidente do grupo Amorim), criada, em 1983, por Pehr Gyllenhammar da Volvo, Wisse Dekker da Philips e Umberto Agnelli da Fiat, que tem como objectivo principal contribuir para o fortalecimento da economia europeia, sobretudo no que concerne à melhoria da sua posição concorrencial a nível do comércio internacional.

A iniciativa desta investigação - que teve o apoio expresso das instituições referidas - partiu de Bertrand Collomb, presidente-director geral da Lafarge Coppée e presidente do grupo Éducation de la Table Rond des Industriels Européens, e de Bruno Dufour, director geral da referida escola superior de Lyon. A investigação científica propriamente dita foi realizada por um grupo de professores desta mesma escola. $O$ universo das entrevistas e opiniões estendeu-se a cinquenta e três presidentes e directores gerais, bem como a directores de recursos humanos de trinte e cinco sociedades internacionais, com sede em 14 países europeus. Dado o objectivo do estudo - como já referimos, visava saber se na Europa se praticava um estilo de gestão diferente do japonês ou americano - , foram também entrevistados alguns dirigentes e gestores de nacionalidade americana e japonesa, todos responsáveis por empresas destes países. Os nomes das empresas e dos dirigentes entrevistados, excepto os que preferiram manter o anonimato, constam de uma lista, publicada no livro, em anexo.

Estamos, portanto, perante um estudo de grande envergadura. Se, com este estudo, se pretendia provar que a Europa, mercê da sua história e da sua cultura, tinha uma forma diferente de conduzir as suas empresas, então o livro acaba por confirmar isto mesmo. E fá-lo, arriscamos dizê-lo, quando tudo indica ter sido esse o desejo e a convicção do conjunto dos responsáveis por esta investigação. Surge-nos, por isso, uma interrogação: porquê então o livro? Porquê, se à partida se conhecia o resultado, todo o aparato desta investigação. Ora, aqui é que está a importância deste livro. Pois, embora todos estivessem convencidos de que a Europa, mercê da sua história, dos seus costumes - e apesar das influências que os modelos de gestão dos dois rivais sempre tiveram (e continuam a ter) - - tinha uma arte algo diferente de gerir os seus negócios, era necessário sistematizar bem essas diferenças e, sobretudo, criar, com esta investigação, uma dinâmica própria 
que leve as instituições de ensino, particularmente as de gestão, os empresários, os quadros superiores, etc., a reflectir sobre a importância destas questões. Reflexão que, assim o pretendem os seus autores, deve conduzir à emergência de um modelo de gestão europeu. Não está, portanto, em causa provar a diferença de gerir dos europeus, o que este livro pretende é muito mais do que isso: acelerar o processo que conduza a um modelo de gestão mais condizente com aquilo que se julga ser os interesses das empresas europeias. Este modelo, diz, na introdução ao livro, Bertrand Collomb, «ne se substituira pas aux modeles nacionaux. Il leur ajoutera simplement une dimension: une façon commune d'être européen» (p.10).

Ora, nesta mensagem é que está a principal riqueza e, paradoxalmente, o ponto fraco deste livro. Ou seja, todos sentimos a necessidade de que a Europa se torne mais competitiva, face aos principais concorrentes, todos reconhecemos que uma Europa unida - tendo em conta que os outros parceiros da tríade, sobretudo o Japão, respondem com culturas mais homógeneas - ganhará vantagens. Mas de que Europa falamos nós? Da Europa a uma, a duas, a três velocidades? De uma Europa, com 12,15 - como actualmente - 20 ou mais países?

Por outro lado, de duas coisas, apenas, estamos certos: a Europa, como um todo, é muito diferente entre si. Apenas quem vê de fora a julga semelhante. Será isto suficiente - ainda que pensando apenas no quadro dos países que compõem a U.E. e com o apoio desta - para fazer emergir uma maneira de ser europeia e paralelamente um modelo de gestão que possamos dizer também europeu? Resta esperar para ver. $O$ livro que aqui comentámos tem pelo menos o mérito de equacionar com rigor estas questões, sem deixar de vincar algo com o qual não podemos deixar de estar de acordo: afinal de contas a diversidade cultural da Europa representa uma riqueza única. $\mathrm{E}$ assim, a existir um modelo de gestão europeu, este tem que saber aproveitar esta característica de respeito pela diversidade. Só deste modo, lembra Bertrand Colomb, poderemos «prendre conscience de nos réalités culturelles et de leur influence sur nos modes de gestion. Si nous devenons plus conscients de nos caractéristiques européens, de leurs forces, de leurs faiblesses et de leurs ambigüités, nous en tierons un meilleur parti pour la valorisation de nos avantages comparatifs internationaux» (p.10)

2. Sobre a obra Limites à competição gostaríamos de acrescentar, ao que já sobre ela dissemos, que se trata de um trabalho sério, com a particularidade de ter conseguido juntar à volta da mesma problemática, nada menos que dezanove autores. A responsabilidade do livro é do denominado Grupo de Lisboa - grupo criado por proposta do Dr. Riccardo Pettrela, director do Programa FAST da Comissão das Comunidades Europeias e professor na Universidade Católica de Lovaina e que mereceu o apoio, em Portugal, da Fundação Calouste Gulbenkian -, grupo de reflexão bastante heterogéneo na sua composição, pois dele 214 fazem parte dezanove membros, com diferentes formações académicas e profis- 
sionais que vão desde actividades empresariais, na administração, em organizações internacionais, até ao mundo universitário. Também as suas nacionalidades são diversificadas, desde o Japão (3), Europa Ocidental (9) — entre estes, dois são portugueses (João Caraça e Joel Serrão) - e América do Norte (7). Ainda assim, O Grupo de Lisboa é intencionalmente composto por membros do denominado «Mundo Triádico», pretendendo, desta forma, «aludir à responsabilidade e à capacidade dos países mais poderosos e desenvolvidos do mundo de enfrentarem os novos problemas e perspectivas globais». E os problemas de hoje advêm, no entender destes autores, sobretudo da escalada da competição - conceito preferido pelos autores ao de concorrência - , no quadro de uma crescente globalização económica e social do mundo. Advertem, ainda na mesma linha, que, caso não se inverta esta tendência, não tarda que a nova economia global mais pareça «um campo de batalha entre gigantes económicos, onde não há lugar para compaixão ou descanso». A ser isto, a «competição já não é a descrição de um modo de funcionamento de configuração particular de mercado (um mercado concorrencial)»; isto é, «Ser competitivo (...) deixou de ser um meio», a competição «adquiriu um estatuto de crença universal, de ideologia» (p.14).

Mas este livro não se limita a denunciar. A primeira parte do livro é toda ela dedicada aos condicionalismos da emergência da «Nova era da competição», bem como à criação de um mundo global. Sem deixar de reconhecer que a globalização económica se faz hoje de acordo com três motores: liberalização, privatização e desregulamentação. Para concluir que, desta forma, «toda a gente está a tentar ser concorrencial, em tudo e contra todos, numa escala global» (p.63).

Um dos capítulos mais interessantes deste livro (Cap.III) é aquele em que os autores colocam, sem rodeios, a seguinte questão: poderá a competição governar o planeta? Para de pronto concluírem, traçando cenários a prazo, que a competição não pode governar o planeta: «a competição constitui uma resposta claramente insuficiente e inadequada para as novas formas de coexistência e de co-desenvolvimento, exigidas por um mundo finito e por um sistema global cada vez mais interdependente e interactivo: o papel da competitividade, enquanto modalidade duma específica configuração de mercado, tem que ser repensado e redefinido à luz das condições e dinâmicas do novo "mundo global"» (p.155).

Que fazer então, qual o caminho para uma governação global efectiva? A isto tentam responder os autores no capítulo final. Defendendo uma governação mais cooperativa, a que se junta uma proposta de quatro contratos sociais globais:

- o contrato para as necessidades básicas;

- o contrato cultural;

- o contrato democrático;

- o contrato do planeta terra. 
Pelo exposto, escusado será repetir que ambas as obras aqui tratadas, aparentemente com perspectivas opostas, são de especial interesse para a compreensão do mundo de hoje. Escusado será também dizer que estas obras interessarão a um público bem mais vasto do que, porventura, aquele a que tendencialmente se destina.

António Rafael Amaro 